\title{
VALIDACIÓN DE PRODUCTOS SATELITALES A PARTIR DE MEDICIONES IN SITU PARA EL MONITOREO DE COBERTURAS DEL SUELO EN EL SUR DE LA REGIÓN PAMPEANA
} (ARGENTINA)

\begin{abstract}
Federico Ferrelli
Instituto Argentino de Oceanografía (IADO), Universidad Nacional del Sur (UNS)-CONICET Bahía Blanca Argentina. Departamento de Geografía y Turismo, Universidad Nacional del Sur (UNS).
\end{abstract}

fferrelli@criba.edu.ar

Andrea Soledad Brendel Instituto Argentino de Oceanografía (IADO), Universidad Nacional del Sur (UNS)-CONICET Bahía Blanca Argentina. Departamento de Agronomía, Universidad Nacional del Sur (UNS). asbrendel@iado-conicet.gob.ar

Gerardo Miguel Eduardo Perillo Instituto Argentino de Oceanografía (IADO), Universidad Nacional del Sur (UNS)-CONICET Bahía Blanca Argentina. Departamento de Geología, Universidad Nacional del Sur (UNS). gmeperillo@criba.edu.ar

María Cintia Piccolo Instituto Argentino de Oceanografía (IADO), Universidad Nacional del Sur (UNS)-CONICET Bahía Blanca Argentina. Departamento de Geografía y Turismo, Universidad Nacional del Sur (UNS). ofpiccol@criba.edu.ar

\begin{abstract}
RESUMEN
La delimitación de las coberturas del suelo es una actividad costosa que requiere de instrumental específico. En este contexto, el objetivo de este estudio fue analizar la precisión y exactitud de productos satelitales de cobertura del suelo con respecto a un mapa confeccionado con mediciones in situ en la cuenca del río Sauce Grande (Argentina). Para ello, se realizaron cinco viajes de campo durante el año 2018 y se tomaron muestras georeferenciadas y firmas espectrales de las coberturas del suelo. Complementariamente, se calcularon índices de vegetación, suelo y agua a partir del procesamiento de imágenes satelitales Landsat 8. Con la reflectancia adquirida a campo y el comportamiento espectral de cada cobertura, se identificaron muestras espaciales necesarias para realizar una clasificación supervisada. Posteriormente, se descargaron los productos MODIS-Landcover y ESA-Landcover y se diseñaron mapas de coberturas del suelo estimadas. Se estableció un tamaño de píxel de $300 \mathrm{~m}$ para los tres productos satelitales y se aplicó con una matriz de confusión del tipo pixel por pixel para compararlos. Los resultados permitieron establecer que el MODIS-Landcover es un producto útil para el monitoreo de cultivos y pastizales, mientras que el ESA-Landcover para la expansión urbana y las variaciones del agua superficial.
\end{abstract}

Palabras clave: Firmas espectrales. Imágenes Landsat. MODIS-Landcover. ESALandcover. Matriz de confusión.

\section{SATELLITE PRODUCTS VALIDATION THROUGH IN SITU MEASUREMENTS FOR MONITORING LAND COVERS IN THE SOUTH OF PAMPAS (ARGENTINA)}

\begin{abstract}
The study of regional-scale land covers is an expensive activity that requires specific equipment. This work aimed to analyze the precision and the accuracy between satellite products and a land cover map obtained using in situ measurements in the Sauce Grande river basin (Argentina). In order to do so, we carried out five field trips during 2018 to identify land covers. It was studied the reflectance of each class from georeferenced samples acquired with a spectrometer and a GPS. Besides, spectral indices of vegetation, water, and soil were calculated to analyze the spectral behavior of each class. With this information, we delimited
\end{abstract}


Validación de productos satelitales a partir de mediciones in situ para el monitoreo de coberturas del suelo en el sur de la Región Pampeana (Argentina)
Federico Ferrelli

Andrea Soledad Brendel

Gerardo Miguel Eduardo Perillo María Cintia Piccolo

regions of interest to perform the supervised method. Subsequently, we downloaded the MODIS and ESA Landcover products. Then, we established a pixel of 300 meters for the three maps with matrix metrics. The Kappa coefficient, the overall accuracy, as well as the user and producer ones, were calculated to evaluate the estimated land cover against the measured ones. Results showed that MODIS-Landcover presents excellent agreements for determining crops and grasslands, while ESA-Landcover for urban expansion and water bodies.

Keywords: Spectral signatures. Landsat images. MODIS-Landcover. ESA-Landcover. Confusion matrix.

\section{INTRODUCCIÓN}

El estudio de las coberturas del suelo permite orientar políticas destinadas al manejo y uso de los recursos naturales y tomar decisiones destinadas al ordenamiento sustentable del territorio (ALRABABAH \& ALHAMAD, 2006). En este contexto, la teledetección representa una herramienta necesaria para determinar las cubiertas terrestres (RODRIGUEZ-GALIANO \& CHICA-RIVAS, 2014) y evaluar, por ejemplo, la actividad agrícola, las áreas urbanas y los cuerpos de agua de una región en particular (SREEDHAR et al., 2016).

Las imágenes satelitales permiten obtener un monitoreo global, regional y local de las coberturas del suelo y sus cambios espacio-temporales (BRENDEL et al., 2019). Su importancia recae en su capacidad de monitorear los espacios de forma periódica (dependiendo de su resolución espacial y temporal). El elevado número y diversidad de imágenes satelitales favorecen el estudio de los cambios en el paisaje en cualquier parte del mundo (MANANDHAR et al., 2009). Particularmente, las imágenes satelitales Landsat facilitan la identificación de las coberturas del suelo con buena precisión. Además, tienen una alta resolución espacial, temporal y espectral (CHEN et al., 2015) y se han utilizado con diversos fines. Por ejemplo, para monitorear los rendimientos de los cultivos (DORAISWAMY et al., 2004; LOBELL, 2013), analizar la cobertura forestal (NIRAULA , 2013; SONG et al., 2015), comprender la dinámica de la vegetación (BRENDEL et al., 2017a; ROBINSON et al., 2017), evaluar cambios en las coberturas del suelo (XIUWAN, 2002; GUERCHMAN et al., 2003; MANANDHAR et al., 2009; KOLIOS \& STYLIOS, 2013; BRENDEL et al., 2019), analizar el clima urbano (FERRELLI et al., 2015; PAL \& ZIAUL, 2017) y la dinámica de los cuerpos de agua (TULBURE \& BROICH, 2013; PEKEL et al., 2016; BRENDEL et al., 2017b), entre otros.

Las cuencas hidrográficas funcionan como integradores de los cambios medioambientales que ocurren en el paisaje terrestre. Brindan agua potable a la población, son espacios de recreación y se utilizan para la industria, proveen servicios ecosistémicos y recursos naturales (WILLIAMSON et al., 2009). Por ello, la generación de un mapa de coberturas del suelo con gran precisión y exactitud a escala de cuenca hidrográfica es de gran utilidad para el ordenamiento del territorio.

En la actualidad, se encuentran disponibles productos satelitales que analizan las coberturas del suelo a escala global. Uno de ellos es el derivado de la combinación de los satélites MODIS-Aqua y MODISTerra. El mismo pertenece a la colección MCD12Q1C y es un producto satelital con una resolución espacial de 500 m (The Level-1 and Atmosphere Archive \& Distribution System (LAADS) Distributed Active Archive Center (DAAC)). Por otro lado, la Agencia Espacial Europea (ESA, por sus siglas en inglés) ofrece productos derivados de la combinación de varios satélites. Estos tienen una resolución espacial de 300 metros y están disponibles para el período 1992-2018 (ESA, 2017). La ventaja de ambas fuentes de datos radica en que son de acceso libre y gratuito y se encuentran validados a escala mundial. A pesar de ello, se desconoce, hasta el momento, su precisión para analizar las coberturas del suelo de las cuencas en Argentina, dado que no se han comparado esta fuente de información con los datos medidos a campo. 
Validación de productos satelitales a partir de mediciones in situ para el monitoreo de coberturas del suelo en el sur de la Región Pampeana (Argentina)
Federico Ferrelli

Andrea Soledad Brendel

Gerardo Miguel Eduardo Perillo María Cintia Piccolo

El área de estudio fue la cuenca del río Sauce Grande $\left(4856 \mathrm{~km}^{2}\right)$, localizada en el sur de la Región Pampeana (Argentina) (Figura 1). La misma se emplaza dentro de los climas semiáridos con una precipitación media anual de $705 \mathrm{~mm}$. En las regiones semiáridas del planeta, la óptima producción de los cultivos depende del régimen de las precipitaciones (BENNIOU \& BAHLOULI, 2015). La cuenca presenta como principal actividad económica la agricultura de secano, que en numerosas ocasiones ha sido impactada por la variabilidad pluviométrica (BRENDEL et al., 2019).

La temperatura media anual es $15,5^{\circ} \mathrm{C}$, presentando una diferenciación marcada entre inviernos y veranos. Las características térmicas y pluviométricas favorecen el crecimiento de cultivos de verano, mientras que las horas de frío en el invierno permiten la implementación de cultivos en esta estación del año. Las áreas cultivadas cubren la mayor parte de la cuenca, siendo la cuenca media y baja las que mayores extensiones presentan (BRENDEL, 2020).

Por lo mencionado, el objetivo de este estudio fue validar la precisión de los productos de cobertura del suelo MODIS y ESA con respecto a un mapa diseñado in situ sobre la base de trabajo de campo y el procesamiento digital de imágenes satelitales Landsat 8 OLI-TIRS. Para ello, se analizaron productos pertenecientes al mismo año y se estableció un tamaño de píxel de $30 \mathrm{~m}$ para todas las imágenes de manera tal que sean comparables espacio-temporalmente entre sí. La finalidad fue la de identificar la fuente de información indirecta que mejor se ajusta a lo observado in situ. Los resultados permitirán identificar la exactitud de cada una de estas fuentes para monitorear las variaciones interanuales de las coberturas del suelo en las zonas semiáridas de Argentina.

Figura 1 - Localización de la cuenca del Río Sauce Grande, los sitios de medición y la altura sobre el nivel del mar.

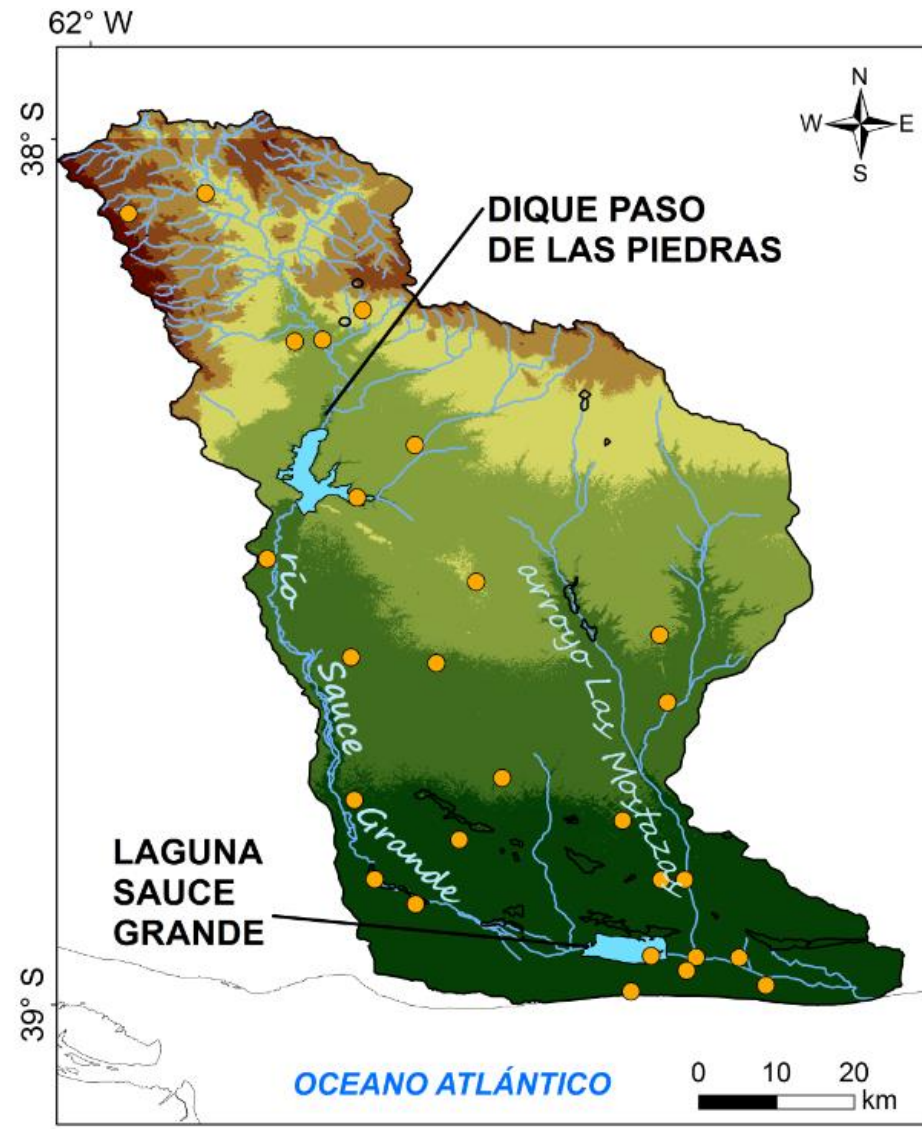

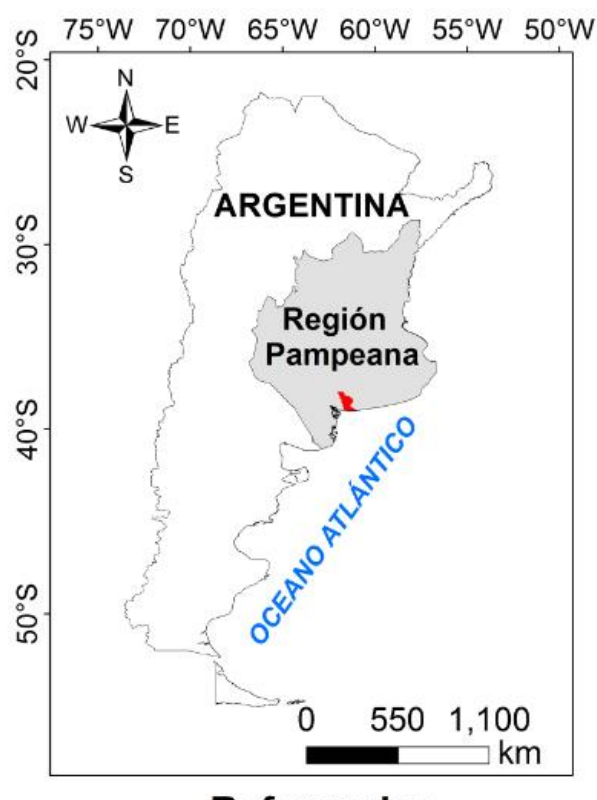

Referencias

- Sitios de medición $\square 250-320$

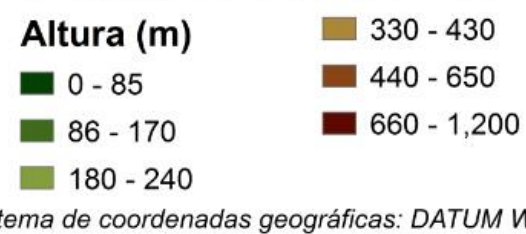

Sistema de coordenadas geográficas: DATUM WGS84 
Validación de productos satelitales a partir de mediciones in situ para el monitoreo de coberturas del suelo en el sur de la Región Pampeana (Argentina)
Federico Ferrelli

Andrea Soledad Brendel

Gerardo Miguel Eduardo Perillo

María Cintia Piccolo

\section{METODOLOGÍA}

El método de trabajo aplicado en este estudio se resume en la Figura 2. El primer paso consistió en la confección de un mapa de coberturas del suelo in situ. Este fue el resultado del procesamiento digital de imágenes satelitales Landsat y un exhaustivo trabajo de campo. Por otro lado, se descargaron los productos satelitales MODIS-Landcover y ESA-Landcover. Posteriormente, se compararon los tres mapas a partir de la aplicación de una matriz de confusión pixel por pixel y el cálculo del índice Kappa y la precisión. Como resultado, se obtuvo el ajuste de cada cobertura (de muy malo a excelente), considerando las estimadas y las obtenidas en trabajo de campo (Figura 2).

Figura 2 - Esquema metodológico aplicado en este trabajo.

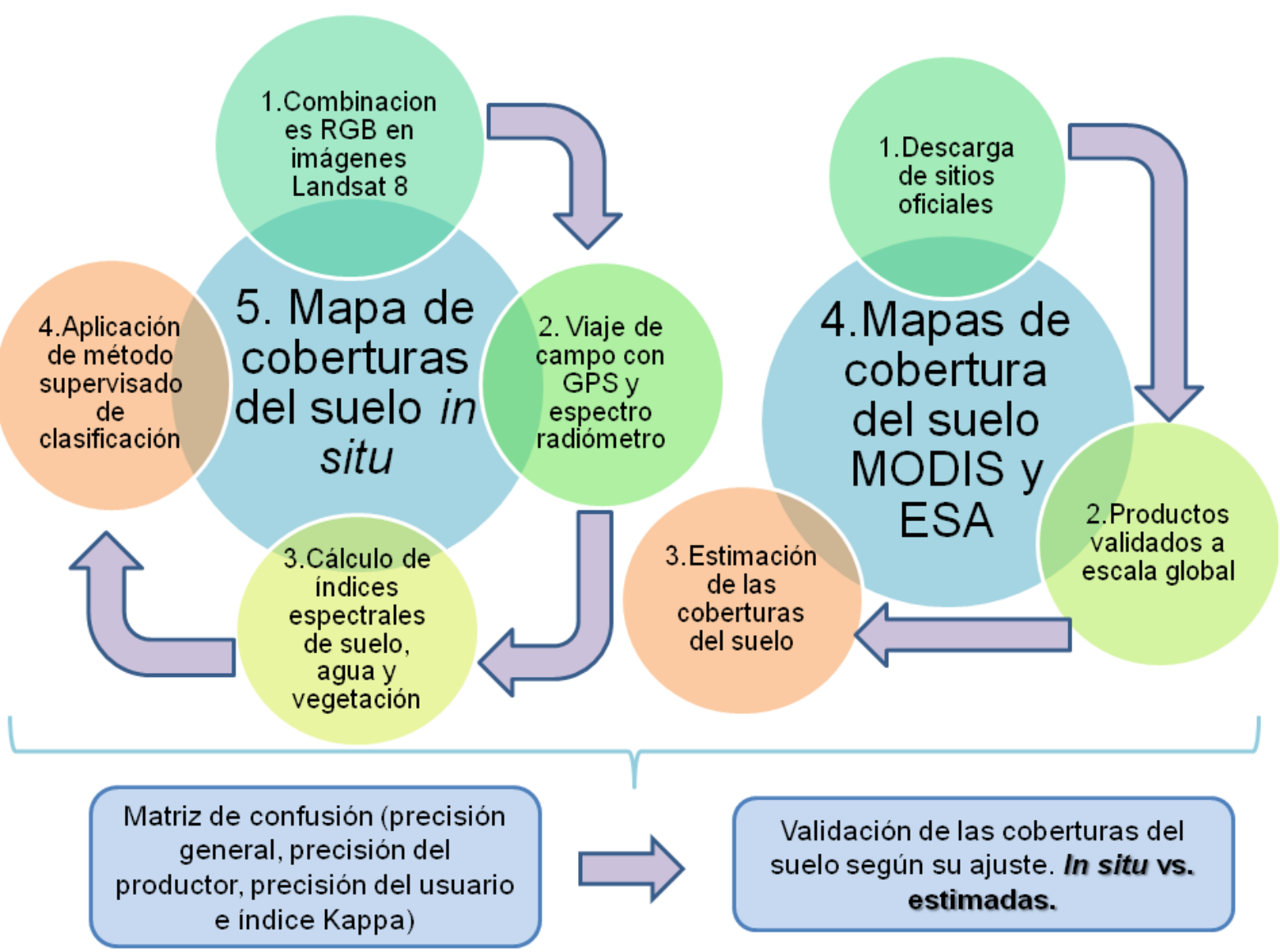

Se confeccionó un mapa de coberturas del suelo a partir del conocimiento, recorrido y muestreo en el terreno. Para ello, se realizaron cinco viajes de campo durante el año 2018. Su confección se basó en el procesamiento digital de imágenes satelitales Landsat 8 OLI-TIRS y el reconocimiento de la reflectividad de superficie adquirido con instrumental de campo. Con esta información, se generó una base de datos robusta para la aplicación de un método de clasificación supervisado de tipo Máxima Verosimilitud. Para seleccionar los sitios de medición a campo, se construyó una clave de identificación a partir de composiciones de color RGB con imágenes satelitales Landsat 8 OLI-TIRS que permitieron identificar seis clases: cultivos, pastizales, cuerpos de agua, vegetación riparia, áreas urbanas y suelos desnudos (Tabla 1). 
Validación de productos satelitales a partir de mediciones in situ para el monitoreo de coberturas del suelo en el sur de la Región Pampeana (Argentina)
Federico Ferrelli

Andrea Soledad Brendel Gerardo Miguel Eduardo Perillo María Cintia Piccolo

Tabla 1 - Coberturas del suelo determinadas a campo mediante observación directa y combinación RGB en imágenes Landsat 8 OLI-TIRS.

\begin{tabular}{|c|c|}
\hline $\begin{array}{c}\text { Cobertura del } \\
\text { suelo }\end{array}$ & Características \\
\hline $\begin{array}{l}\text { Vegetación } \\
\text { riparia }\end{array}$ & $\begin{array}{l}\text { Herbáceas, vegetación espesa, con alta densidad y árboles localizados en las } \\
\text { márgenes de los ríos y los cuerpos de agua. Alguna de sus especies más } \\
\text { predominantes son Stipa y Cortaderia seollana. }\end{array}$ \\
\hline Pastizales & $\begin{array}{l}\text { Áreas con vegetación herbácea natural e implantada destinada a la actividad } \\
\text { ganadera. Se localizan principalmente en la cuenca media y baja y están } \\
\text { compuestos principalmente por Stipa, Festuca pampeana, Poa y Melica. }\end{array}$ \\
\hline Cultivos & $\begin{array}{l}\text { Áreas sembradas con cultivos de verano como de invierno. Las fechas de siembra } \\
\text { de los primeros son en octubre y se cosechan en marzo. Están compuestos } \\
\text { principalmente por girasol, maíz y soja. } \\
\text { Los cultivos de invierno se siembran en junio y se cosechan a finales de agosto. } \\
\text { Los componen el trigo, la cebada y la avena en su mayoría. }\end{array}$ \\
\hline $\begin{array}{l}\text { Cuerpos de } \\
\text { agua }\end{array}$ & Lagunas y reservorios de agua. \\
\hline $\begin{array}{l}\text { Suelo } \\
\text { descubierto }\end{array}$ & $\begin{array}{l}\text { Rocas expuestas sin vegetación localizadas al noroeste y dunas sin vegetación } \\
\text { ubicadas en las costas }\end{array}$ \\
\hline Áreas urbanas & $\begin{array}{l}\text { Zonas urbanas localizadas en la cuenca. Entre ellas: Sierra de la Ventana, Villa } \\
\text { Ventana, Saldungaray, Monte Hermoso, Lastigau y San Román. }\end{array}$ \\
\hline
\end{tabular}

Posteriormente, en cada sitio de medición y mediante la utilización del espectro radiómetro de campo Ocean Optics USB 2000+, se adquirieron firmas espectrales y puntos GNSS, con la finalidad de diferenciar espectralmente estas coberturas. Este instrumento analiza la reflectancia espectral desde los 400 hasta los $1200 \mathrm{~nm}$ con un ancho de banda de 0,34 nm, por lo que registra información en el espectro visible y en el infrarrojo cercano. En una primera instancia, se almacenaron las medidas de reflectividad máximas y las oscuras (blanco y negro) para corregir las posibles variaciones en la respuesta del instrumento. Este procedimiento, se realizó en cada sitio de medición presentado en la Figura 1. El período de muestreo coincidió con el horario del cenit solar.

A continuación, se procesaron imágenes satelitales Landsat 8 OLI-TIRS (Tabla 2). Estas fueron corregidas geométricamente, a partir de la aplicación de la técnica de sitios de control. La misma, se realizó seleccionando 25 puntos estratégicos, considerando que los mismos fueran equidistantes entre sí (CARMONA et al., 2011). Posteriormente, se procedió a realizar su calibración radiométrica con la finalidad de transformar los valores digitales a valores de radiancia al tope de la atmósfera. Para ello, se aplicó la siguiente ecuación:

$$
L_{\lambda s a t}=G_{\lambda} N D_{\lambda}+B_{\lambda}
$$

donde $\lambda$ indica el número de la banda, G y B son el Gain y el Bias que son coeficientes de transformación de los Números Digitales (ND) a valores de radiancia. Estos se encuentran establecidos en la información contenida en las imágenes satelitales. 
Validación de productos satelitales a partir de mediciones in situ para el monitoreo de coberturas del suelo en el sur de la Región Pampeana (Argentina)
Federico Ferrelli

Andrea Soledad Brendel

Gerardo Miguel Eduardo Perillo María Cintia Piccolo

Tabla 2 - Imágenes satelitales Landsat 8 OLI-TIRS utilizadas para la determinación de las coberturas del suelo in situ.

\begin{tabular}{|l|l|}
\hline \multicolumn{1}{|c|}{ Fecha } & \multicolumn{1}{c|}{ Descripción } \\
\hline 15 de noviembre de 2018 & LC08_L1TP_226087_20181103_20181115_01_T1 \\
\hline 1 de octubre de 2018 & LC08_L1TP_226087_20181002_20181010_01_T1 \\
\hline 28 de agosto de 2018 & LC08_L1TP_226087_20180815_20180828_01_T1 \\
\hline 17 de mayo de 2018 & LC08_L1TP_226087_20180511_20180517_01_T1 \\
\hline 20 de marzo de 2018 & LC08_L1TP_226087_20180308_20180320_01_T1 \\
\hline
\end{tabular}

Los valores de radiancia se transformaron en reflectancia al tope de la atmósfera. Para ello, se aplicó el método de Schoerder et al. (2006), asumiendo una superficie lambertiana, libre de nubes y sin considerar los efectos de la atmósfera.

Una vez realizada la corrección radiométrica, se aplicó una corrección atmosférica con la finalidad de eliminar los efectos de la atmósfera sobre los valores obtenidos en los píxeles. Para ello, se aplicó el método de Sustracción de Superficies Oscuras (CHÁVEZ, 1988), aplicando la siguiente ecuación:

$$
\rho_{\lambda S}=\frac{\pi_{(L \lambda s a t-L \lambda \rho)}}{\left(T_{\lambda v}\left(E_{\lambda \text { down }} d^{-2} \cos \theta_{z} T_{\lambda z}+E_{\text {down }}\right)\right)}
$$

donde $L \lambda \rho\left(\mathrm{W} \mathrm{m}^{-2} \mathrm{sr}^{-1} \mu \mathrm{m}^{-1}\right)$ es la radiancia registrada como resultado de la interacción entre la radiación electromagnética y los componentes atmosféricos, $T_{\lambda v}$ es la transmisividad atmosférica desde la superficie hacia el sensor, $T_{\lambda z}$ es la transmisividad atmosférica en la dirección de la iluminación solar y $E_{\text {down }}$ es la irradiancia difusa del cielo hacia abajo $\left(\mathrm{W} \mathrm{m}^{-2} \mu \mathrm{m}^{-1}\right)$.

Este método supone que en la imagen se presentan píxeles con una reflectividad cercana a cero, lo que se identifica como zonas oscuras. Son ejemplos: las aguas claras o profundas, zonas con vegetación altamente densa, entre otras. Los efectos de la atmósfera en la imagen se pueden reconocer fácilmente sobre estos píxeles (SONG et al., 2001; CARMONA et al., 2011). Para aplicar este método fue necesario sustraerle a cada el valor de $L \lambda$ sat el de $L \lambda \rho$ que es el que se deriva de lo referente a lo introducido por la atmósfera. Para ello, se aplicó la siguiente ecuación:

$$
L_{\lambda \rho}=G_{\lambda} N D_{\lambda d a r k}+B_{\lambda}-0,01 \frac{\left(E_{\lambda 0} \cos _{\theta z} T_{\lambda z} T_{\lambda y}\right)}{\left(d^{2} \pi\right)}
$$

donde $N D_{\lambda \text { dark }}$ es el $N D_{\lambda}$ mínimo de cada banda del Landsat 8 OLI-TIRS para cada región de interés. El valor surge de un mínimo de 1000 píxeles. Este método considera una atmósfera Rayleigh sin aerosoles y una reflectividad del $1 \%$ para el objeto oscuro (CHÁVEZ, 1988). Por otro lado, $T_{\lambda z}$ y $T_{\lambda y}$ se calcularon considerando las siguientes ecuaciones:

$$
\begin{aligned}
& T_{\lambda v}=\exp \left(\frac{-T_{\lambda z}}{\cos _{\theta z}}\right) \\
& T_{\lambda z}=\exp \left(\frac{-T_{\lambda r}}{\cos _{\theta z}}\right)
\end{aligned}
$$

donde $T_{\lambda r}$ es el espesor óptico para la dispersión Rayleigh, considerando:

$$
T_{\lambda r}=\frac{0,008569}{\left(\lambda_{m}^{4}\left(1 \lambda_{m}^{2}+0.013 \lambda_{m}^{4}\right)\right.}
$$


Validación de productos satelitales a partir de mediciones in situ para el monitoreo de coberturas del suelo en el sur de la Región Pampeana (Argentina)
Federico Ferrelli

Andrea Soledad Brendel Gerardo Miguel Eduardo Perillo María Cintia Piccolo

donde $\lambda_{r}$ (en $\left.\mu \mathrm{m}\right)$ es la longitud de onda de cada banda y $E_{\lambda \text { down }}$ es un parámetro nulo dado que su contribución se puede considerar como insignificante (SONG et al., 2001).

Una vez corregidas las imágenes satelitales, se aplicaron seis índices espectrales de suelo, agua y vegetación. Está demostrado que estos permiten obtener una mejor delimitación de las coberturas del suelo (GUERCHMAN et al., 2003; BRENDEL et al., 2019) (Tabla 3).

Tabla 3 - Índices espectrales aplicados sobre las imágenes satelitales Landsat 8 OLI-TIRS para analizar el comportamiento espectral de las distintas coberturas del suelo.

\begin{tabular}{|c|c|c|}
\hline İndices & Ecuación & Autor \\
\hline $\begin{array}{l}\text { Índice nomalizado de } \\
\text { vegetación (NDVI) }\end{array}$ & $\begin{array}{l}\qquad N D V I=\frac{N I R-R}{N I R+R} \\
\text { donde NIR es la banda del Infrarrojo Cercano y R la del } \\
\text { Rojo. }\end{array}$ & Rouse et al. (1974) \\
\hline $\begin{array}{l}\text { Índice de vegetación } \\
\text { mejorado EVI) }\end{array}$ & $\begin{array}{l}\qquad E V I=\left(\frac{N I R-R}{N I R+C_{1} * R-C_{2} * B+L}\right) \\
\text { donde NIR es la banda del Infrarrojo Cercano, R: la del } \\
\text { rojo, C1 y C2 son coeficientes necesarios para corregir la } \\
\text { dispersión atmosférica, } \mathrm{L} \text { es el factor de corrección del } \\
\text { suelo y B es la banda azul. }\end{array}$ & Liu \& Huete (1995) \\
\hline $\begin{array}{l}\text { Índice ajustado de } \\
\text { suelo y vegetación } \\
\text { (SAVI) }\end{array}$ & $\begin{array}{l}\qquad S A V I=\left(\frac{N I R-R}{(N I R+R+L) *(1+L)}\right) \\
\text { donde NIR es el Infrarrojo Cercano, R es el Rojo y L es un } \\
\text { factor de corrección del suelo }\end{array}$ & Qi et al. (1994) \\
\hline $\begin{array}{l}\text { Índice modificado de } \\
\text { suelo y vegetación } \\
\text { (MSAVI) }\end{array}$ & $\begin{array}{l}\quad M S A V I=\frac{2 * N I R+1-\sqrt{(2 * N I R+1)^{2}-8 * N I R-R}}{2} \\
\text { donde NIR es el INfrarrojo Cercano y } \mathrm{R} \text { es el Rojo. }\end{array}$ & \\
\hline $\begin{array}{l}\text { Índice normalizado de } \\
\text { diferencia de humedad } \\
\text { de suelos (NDMI) }\end{array}$ & $\begin{array}{l}\qquad N D M I=\frac{N I R-S W I R}{N I R+S W I R} \\
\text { donde NIR es el Infrarrojo Cercano y SWIR es el Infrarrojo } \\
\text { Medio. }\end{array}$ & $\begin{array}{l}\text { Wilson \& Sader } \\
\text { (2002) }\end{array}$ \\
\hline $\begin{array}{l}\text { Índice normalizado de } \\
\text { agua (NDWI) }\end{array}$ & $\begin{array}{l}\qquad N D W I=\frac{G-N I R}{G+N I R} \\
\text { donde NIR es el Infrarrojo Cercano y G es la banda del } \\
\text { verde. }\end{array}$ & McFeeters (1996) \\
\hline
\end{tabular}

A partir de la evaluación de las muestras adquiridas con el espectroradiómetro, junto con la información de la respuesta espectral determinada con los índices para cada cobertura del suelo, se delimitaron muestras espaciales o áreas de interés. Estas fueron la base para aplicar el método de clasificación supervisado de Máxima Verosimilitud y diseñar el mapa de coberturas del suelo in situ. Se seleccionó

Caminhos de Geografia $\quad$ Uberlândia-MG $\quad$ v. 21, n. 76 $\quad$ Ago/2020 $\quad$ p. 190-207 Página 196


Validación de productos satelitales a partir de mediciones in situ para el monitoreo de coberturas del suelo en el sur de la Región Pampeana (Argentina)
Federico Ferrelli

Andrea Soledad Brendel

Gerardo Miguel Eduardo Perillo María Cintia Piccolo

este método dado que es el más preciso para discriminar las coberturas del suelo en la cuenca del río Sauce Grande (BRENDEL et al., 2019).

Finalmente, se descargaron los productos MODIS MCD12Q1C (h13, v12) de coberturas del suelo provisto por LAADS-DAAC (https://ladsweb.modaps.eosdis.nasa.gov/) y los de la ESA (maps.elie.ucl.ac.be/CCl/viewer/download/ESACCI-LC-Ph2-PUGv2_2.0.pdf) correspondientes al año 2018. Para que todas las matrices sean comparables entre sí, se estableció un valor de píxel de 300 metros y se unificaron las nomenclaturas de las coberturas del suelo. Con el objetivo de evaluar la precisión de los productos respecto del mapa in situ, se realizó una matriz de confusión pixel por pixel. Se calcularon distintos parámetros de estimación como i) la precisión general que indicó el porcentaje de píxeles correctamente clasificados, ii) la precisión del productor que expresó la probabilidad de que un píxel clasificado como clase $\mathrm{x}$ realmente pertenezca a esa clase, y iii) la precisión del usuario que hizo referencia a la probabilidad de que un píxel clasificado como $\mathrm{x}$ corresponda realmente a dicha clase (NICLÒS CORTS et al., 2010).

Las tres matrices (o mapas) resultantes (de aquí en adelante denominados: in situ, MODIS-Landcover y ESA-Landcover) fueron comparadas con el índice Kappa. Este es una medida de precisión que computa la exactitud, en este caso, entre los productos MODIS y ESA con respecto a la clasificación in situ, eliminando lo que cabría esperar por el azar. El índice Kappa oscila entre 0 y 1 y según Monserud \& Leemans (1992) tiene una clasificación cualitativa, considerando lo detallado en la Tabla 4.

Tabla 4 - Caracterización de los resultados obtenidos con el Índice Kappa. Modificado de Monserud \& Leemans (1992).

\begin{tabular}{|c|c|}
\hline Índice Kappa & Tipo de ajuste \\
\hline$<0,4$ & Muy malo \\
\hline$>0,4<0,55$ & Moderado \\
\hline$>0.55<0,7$ & Bueno \\
\hline$>0,7<0,85$ & Muy bueno \\
\hline$>0,85$ & Excelente \\
\hline
\end{tabular}

\section{RESULTADOS}

\section{Comportamiento espectral de las coberturas del suelo}

El comportamiento espectral medio de las coberturas del suelo durante el año 2018 se presenta en la Figura 3. Las mismas tuvieron una marcada diferenciación entre sí (Figura 3A). Si bien algunas coberturas registraron valores similares en el visible (Figura 3B), estas fueron claramente diferenciadas en el Infrarrojo Cercano (IRC) (Figura 3C).

La vegetación riparia, los cultivos y los pastizales registraron un comportamiento similar a lo largo de todo el espectro. Sin embargo, la primera cobertura presentó los valores máximos en el IRC, siendo fácilmente diferenciada del resto (Figura $3 \mathrm{C}$ ). Los cultivos mantuvieron picos máximos y más elevados que los pastizales en el verde $(550 \mathrm{~nm})$ y en el IRC (9,2 y 43,5\%, respectivamente) (Figura 3 A y B). 
Validación de productos satelitales a partir de mediciones in situ para el monitoreo de coberturas del suelo en el sur de la Región Pampeana (Argentina)
Federico Ferrelli

Andrea Soledad Brendel Gerardo Miguel Eduardo Perillo María Cintia Piccolo

Por otro lado, los suelos desnudos mostraron una firma espectral típica de este tipo de coberturas con valores constantes a lo largo de todo el espectro ( $\cong 15 \%$ ) (Figura 3A). Lo mismo, se observó con el agua, con valores bajos en todo el espectro. El pico máximo se identificó en el visible (5,2 \%) (Figura $3 A)$.

Figura 3 - Firma espectral para cada cobertura del suelo (A) Espectro completo, (B) Visible, (C) Infrarrojo Cercano.

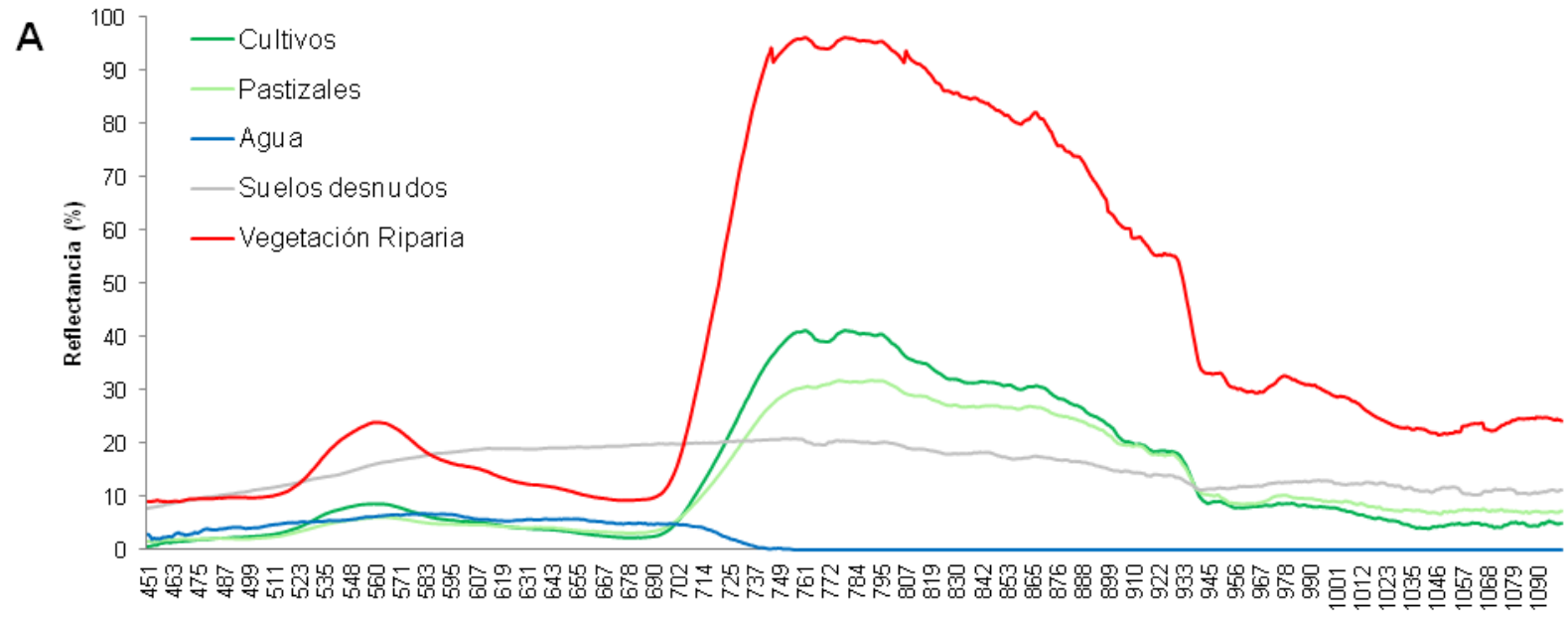

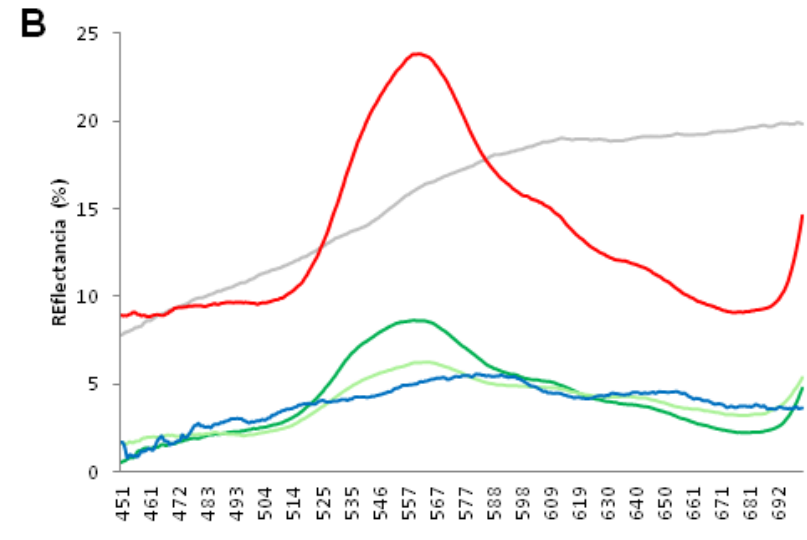

$\mathrm{nm}$

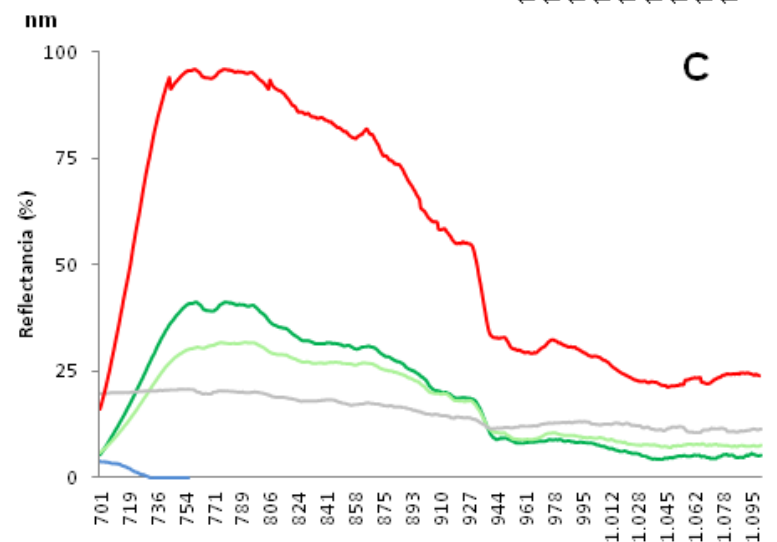

$\mathrm{nm}$

Una vez analizado el comportamiento de la reflectancia de las coberturas del suelo, se procedió a evaluar su variación en los seis índices espectrales (Figura 4). El agua presentó valores negativos de NDVI $(-0,22 \pm 0,04)$ y positivos de NDWI $(0,34 \pm 0,18)$ y NDMI $(0,52 \pm 0,05)$ durante todo el año. Los cultivos presentaron valores negativos de NDWI $(-0,32 \pm 0,18)$, altos de MSAVI $(0,92 \pm 0,05)$ y mayores registros de NDVI que de EVI en relación con la vegetación riparia $(0,41 \pm 0,07,0,44 \pm 0,08$ y $0,51 \pm$ 0,08 y $0,48 \pm 0,06$, respectivamente) (Figura 4 ).

Por otra parte, el pastizal mostró valores homogéneos de NDVI a lo largo del año $(0,25 \pm 0,06)$, el SAVI $(0,15 \pm 0,02)$ y el NDMI $(-0,22 \pm 0,04)$, permitiendo diferenciarlos de los cultivos y la vegetación riparia. El suelo desnudo tuvo valores altos y contantes de MSAVI $(0,96 \pm 0,03)$ e intermedios y constantes de SAVI $(0,16 \pm 0,02)$. Estas características favorecieron la delimitación con mayor precisión de las coberturas del suelo en la cuenca del río Sauce Grande durante el año 2018 (Figura 4). 
Validación de productos satelitales a partir de mediciones in situ para el monitoreo de coberturas del suelo en el sur de la Región Pampeana (Argentina)
Federico Ferrelli

Andrea Soledad Brendel Gerardo Miguel Eduardo Perillo María Cintia Piccolo

Figura 4 - Comportamiento espectral de las coberturas del suelo durante el año 2018.

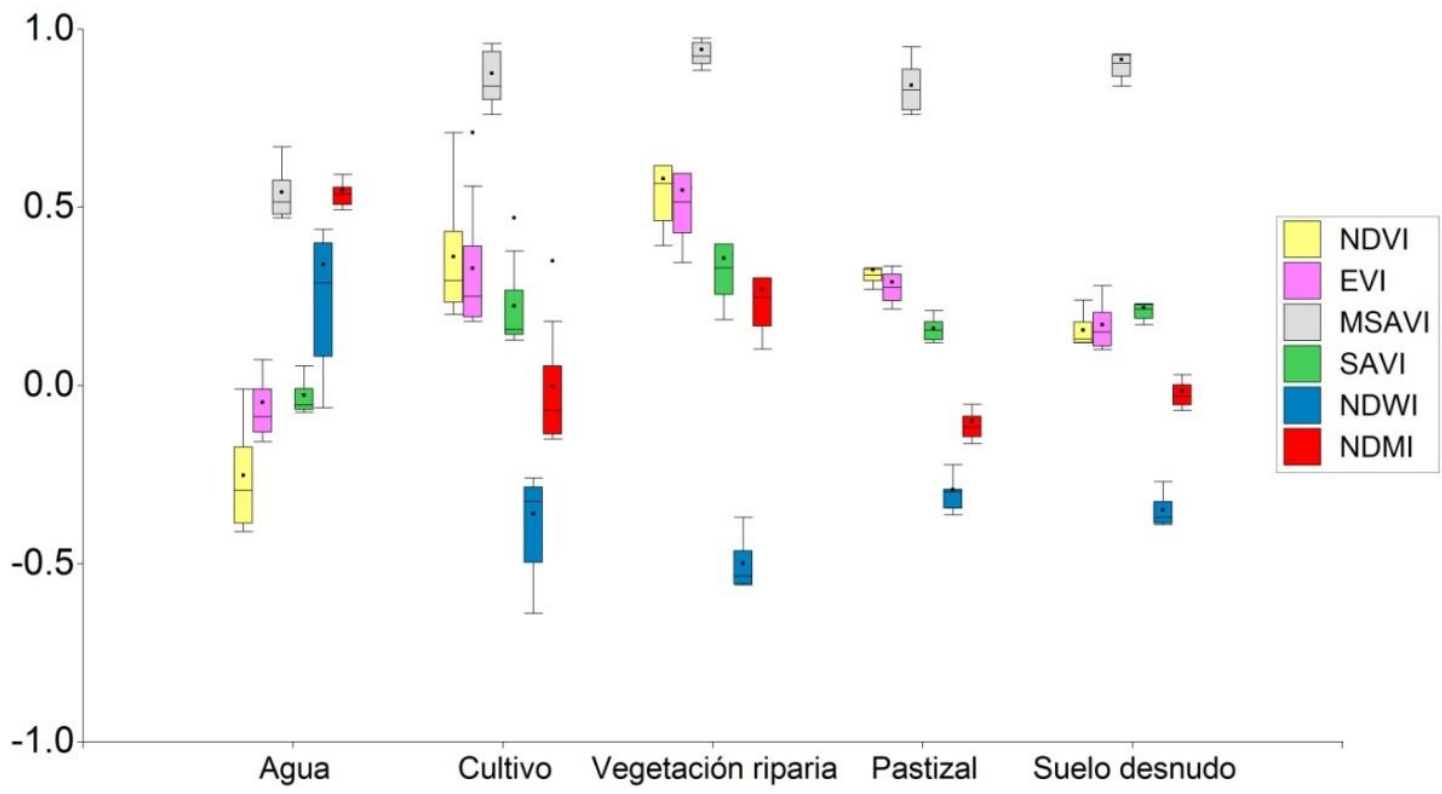

Posteriormente, se aplicó el método de Máxima Verosimilitud sobre las imágenes satelitales Landsat 8 OLI-TIRS, utilizando como base de la clasificación las muestras georeferenciada resultantes de las firmas espectrales y los seis índices (Figura 3 y 4). Este arrojó un mapa de coberturas del suelo con una precisión general de 99,1\%. El Índice Kappa indicó la existencia de excelentes ajustes $(0,98)$. Se observó que en la cuenca del río Sauce Grande predominaron los cultivos $\left(2352 \mathrm{~km}^{2}\right)$, seguido de pastizales $\left(1743,3 \mathrm{~km}^{2}\right)$, suelo al descubierto $\left(382,5 \mathrm{~km}^{2}\right)$, vegetación riparia $\left(247,1 \mathrm{~km}^{2}\right)$, agua $(78,8$ $\mathrm{km}^{2}$ ) y áreas urbanas $\left(18,7 \mathrm{~km}^{2}\right)$ (Figura $\left.5 \mathrm{~A}\right)$. Finalmente, la precisión del productor y la del usuario presentaron valores superiores a $96 \%$, indicando que todas las coberturas discriminadas in situ tuvieron una excelente delimitación (Tabla 5).

Tabla 5 - Matriz de confusión obtenida del procesamiento de imágenes Landsat 8 OLI-TIRS con el método de Máxima Verosimilitud.

\begin{tabular}{|l|r|}
\hline $\begin{array}{l}\text { Precisión } \\
\text { General }\end{array}$ & $99,12 \%$ \\
\hline $\begin{array}{l}\text { Coeficiente } \\
\text { Kappa }\end{array}$ & 0,9812 \\
\hline
\end{tabular}

Datos in situ (Ground Truth - \%)

\begin{tabular}{|l|r|r|r|r|r|r|}
\hline \multicolumn{1}{|c|}{ Clases } & Cultivos & Pastizales & $\begin{array}{c}\text { Suelo al } \\
\text { descubierto }\end{array}$ & $\begin{array}{c}\text { Vegetación } \\
\text { riparia }\end{array}$ & \multicolumn{1}{c|}{ Agua } & $\begin{array}{c}\text { Áreas } \\
\text { urbanas }\end{array}$ \\
\hline Cultivos & 98,3 & 1,6 & 0,3 & 1,2 & 0 & 0 \\
\hline Pastizales & 4 & 97 & 2,5 & 0,3 & 0 & 0 \\
\hline $\begin{array}{l}\text { Suelo al } \\
\text { descubierto }\end{array}$ & 0 & 1,4 & 95,1 & 0,1 & 0 & 1,2 \\
\hline $\begin{array}{l}\text { vegetación } \\
\text { riparia }\end{array}$ & 0,7 & 0 & 0 & 98,4 & 0 & 0 \\
\hline Agua & 0 & 0 & 0 & 0 & 100 & 0 \\
\hline Áreas urbanas & 0 & 0 & 2,1 & 0 & 0 & 98,8 \\
\hline Total & 100 & 100 & 100 & 100 & 100 & 100 \\
\hline
\end{tabular}

Caminhos de Geografia

Uberlândia-MG

v. 21, n. 76

Ago/2020

p. $190-207$

Página 199 
Validación de productos satelitales a partir de mediciones in situ para el monitoreo de coberturas del suelo en el sur de la Región Pampeana (Argentina)
Federico Ferrelli

Andrea Soledad Brendel

Gerardo Miguel Eduardo Perillo María Cintia Piccolo

\section{Evaluación de la precisión y la exactitud de los productos satelitales}

A partir de la confección del mapa de coberturas de suelo in situ, se transformó su resolución espacial a 300 metros y se procedió a comparar sus resultados con aquellos obtenidos con MODIS-Landcover y ESA-Landcover. Se observó que la distribución espacial de las coberturas del suelo fue heterogénea en los tres mapas generados. El mapa in situ presentó un mayor grado de detalle al estar realizado sobre una base con una resolución espacial menor (30 m - Landsat 8 OLI-TIRS) (Figura 5A). Como fue esperable debido a las diferencias espaciales entre los productos satelitales, el obtenido del ESALandcover sobreestimó las áreas de cultivos (Figura 5B). Su resolución espacial (300 m) no permitió determinar la existencia de suelos al descubierto sobre la cuenca, sino que los mismos se emplazaron dentro de los pastizales. El mapa derivado del MODIS-Landcover tuvo una mayor heterogeneidad espacial (Figura 5C). Al igual que en el caso anterior, su resolución espacial (500 m) no generó un mapa con el mismo grado de detalle que el obtenido in situ, pero las variaciones entre cultivos y pastizales se evidenciaron en el mapa. Similarmente al caso anterior, los suelos al descubierto fueron parte de la cobertura pastizales (Figura 5B y $\mathrm{C}$ ). El agua estuvo bien definida en los tres mapas, como las ciudades. Esta última categoría evidenció una mayor extensión en el MODIS-Landcover, dado que presentó un área urbana al sur del dique Paso de las Piedras, que en la superficie es inexistente (Figura $5 C)$.

Figura 5 - Distribución espacial de las coberturas del suelo calculadas (A) in situ, (B) con los productos ESA Landcover y $(\mathrm{C})$ con MODIS Landcover.
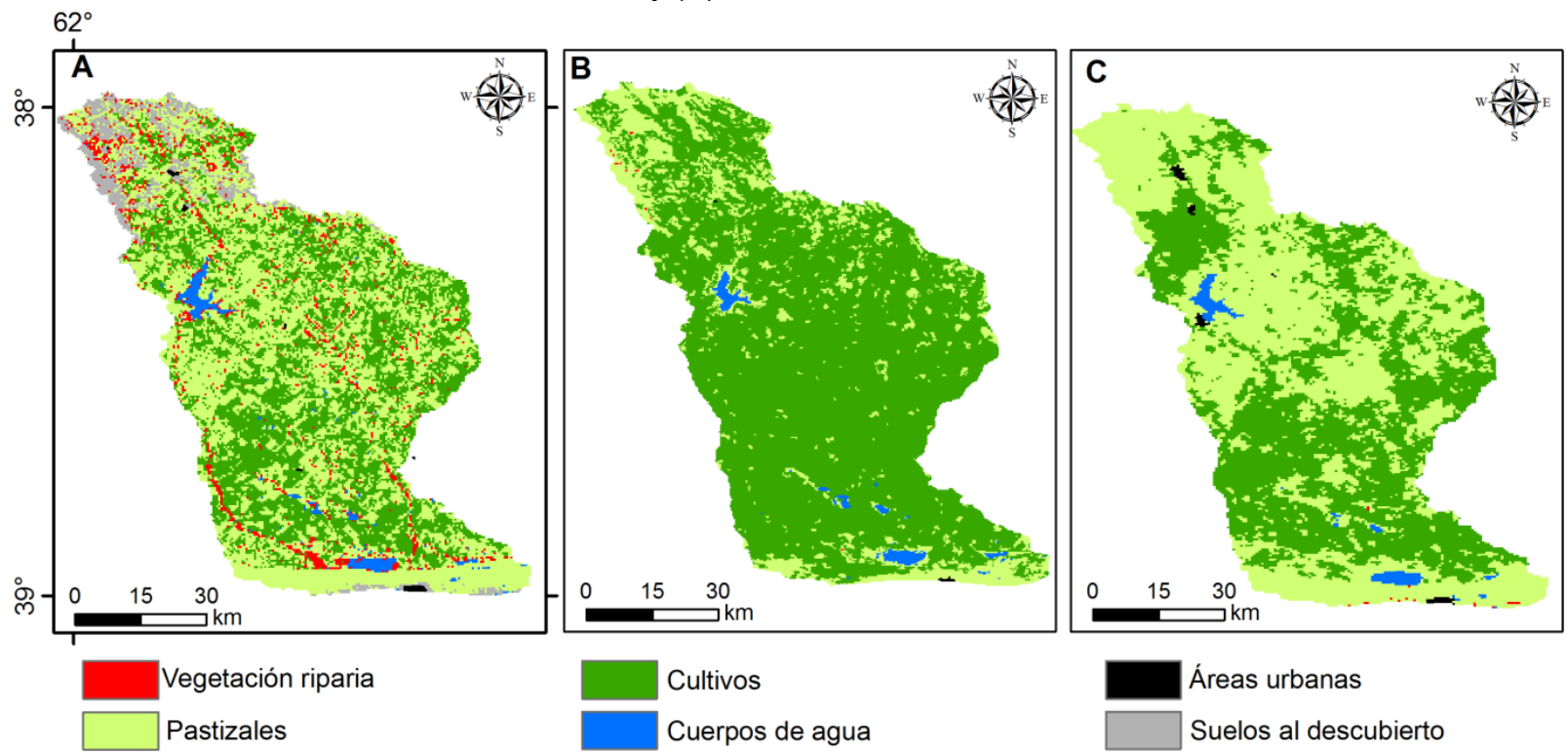

Los cultivos mostraron una área similar entre los resultados obtenidos in situ y los identificados con MODIS-Landcover (35,9 y 44,3\%, respectivamente, es decir, 2382,2 y $2618 \mathrm{~km}^{2}$, respectivamente), mientras que el ESA-Landcover presentó un área menor $\left(876,4 \mathrm{~km}^{2}\right)$. En este último mapa los pastizales abarcaron el $80,1 \%$ del área de la cuenca $\left(3890,7 \mathrm{~km}^{2}\right)$. Esta cubierta fue similar al analizarla con MODIS-Landcover y el mapa in situ (49,1 y 53,9\%, respectivamente) (Figura 6). Cabe destacar que los suelos descubiertos que abarcaron el 7,9 \% de la superficie de la cuenca, no se registraron en los productos satelitales (Figura 7). 
Validación de productos satelitales a partir de mediciones in situ para el monitoreo de coberturas del suelo en el sur de la Región Pampeana (Argentina)
Federico Ferrelli

Andrea Soledad Brendel Gerardo Miguel Eduardo Perillo María Cintia Piccolo

Figura 6 - Área de las coberturas del suelo con mayor superficie $\left(\mathrm{km}^{2}\right)$ identificadas in situ, con MODIS Landcover y con ESA Landover.

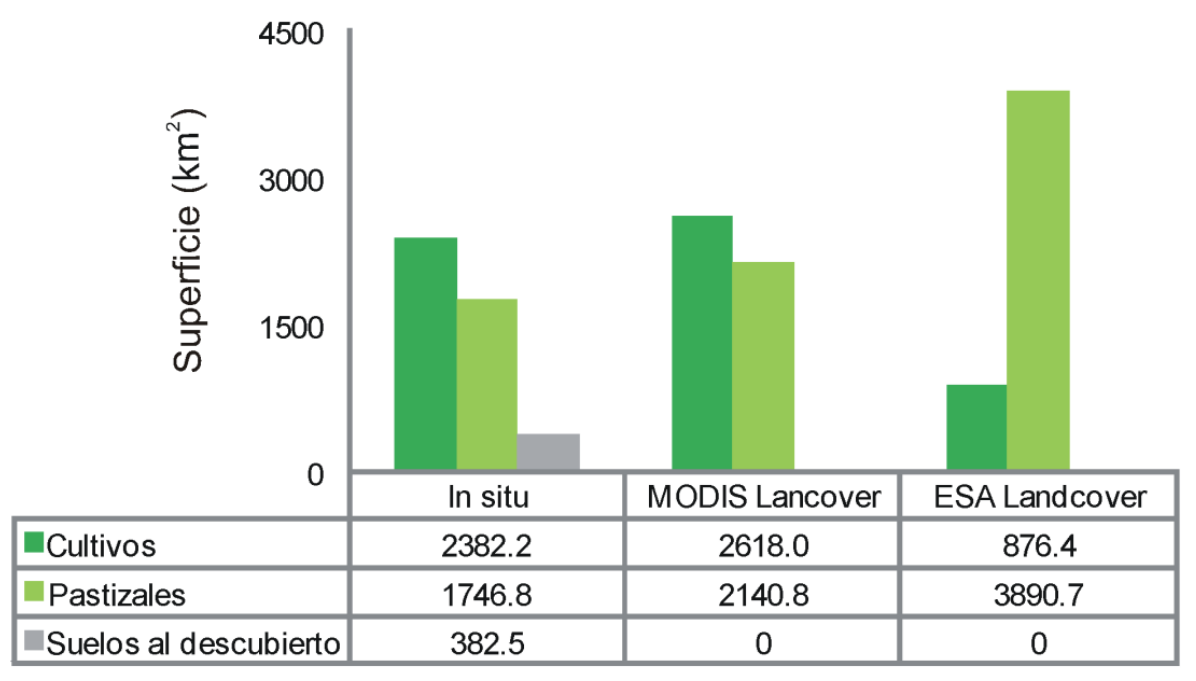

Las áreas urbanas mostraron una superficie similar en los tres casos analizados ( $\cong 0,4 \%$ ). En MODISLandcover fue mayor $\left(19,1 \mathrm{~km}^{2}\right)$, debido a que, como se mencionó anteriormente, en el mismo se identificó como área urbana un sector localizado al sur del dique Paso de las Piedras (Figura 1 y $5 \mathrm{C}$ ). Como se esperaba, las coberturas de agua estuvieron estimadas correctamente, presentando cuerpos de agua en el mismo lugar que los observados en el terreno. Las diferencias en la extensión áreal son producto de las distintas resoluciones espaciales de cada producto. Finalmente, la vegetación riparia ocupó un 5,1 \%, mientras que en MODIS Landcover 0,1\% y en ESA Landcover 0,2\%, mostrando una mala representación espacial (Figura 7). Esta se localizó a los largos de toda la cuenca sobre las márgenes de los ríos. A pesar de ello, esta cobertura fue detectada como pastizal en los mapas MODIS y ESA. Su escasa superficie se ubicó en las proximidades de la costa (Figura 5B y C).

Figura 7 - Extensión areal de las coberturas del suelo con menor superficie $\left(\mathrm{km}^{2}\right)$ identificadas in situ, con MODIS Landcover y con ESA Landover.

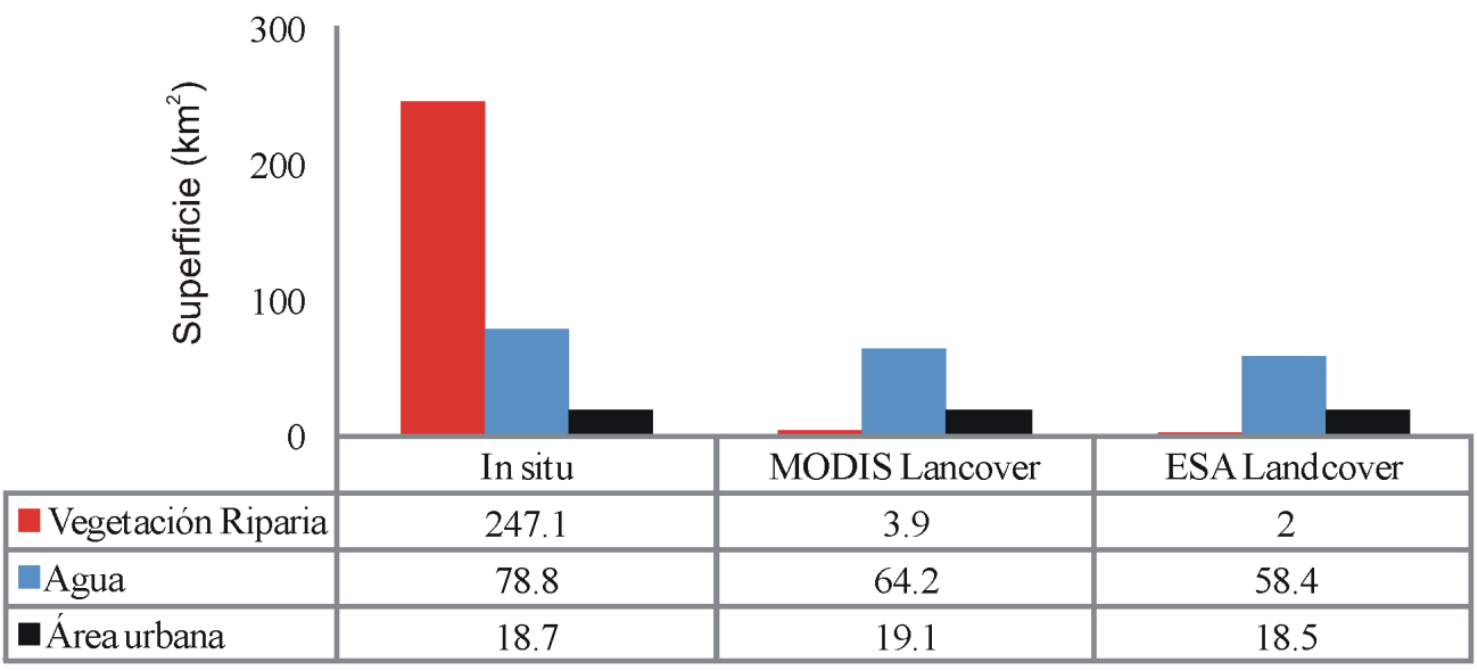


Validación de productos satelitales a partir de mediciones in situ para el monitoreo de coberturas del suelo en el sur de la Región Pampeana (Argentina)
Federico Ferrelli

Andrea Soledad Brendel

Gerardo Miguel Eduardo Perillo María Cintia Piccolo

Al realizar el cruce de matrices píxel por píxel entre el mapa in situ y el de MODIS-Landcover y el de ESA-Landcover, se observaron diferencias importantes. En el primer caso, el coeficiente Kappa fue 0,78 y la precisión general 0,81 , lo que indicó un muy buen ajuste entre ambas matrices. Por otro lado, el producto ESA-Landcover arrojó valores de 0,43 y 0,51, respectivamente, identificando un ajuste moderado.

A partir del análisis de la precisión del productor y del usuario, se determinó que el producto MODISLandcover presentó valores de 86 y $88,2 \%$ para el cultivo, respectivamente. El pastizal arrojó un 92 y $80,2 \%$ y el agua un 93,7 y $97,1 \%$, respectivamente. Esto pone de manifiesto que este producto tiene excelentes ajustes para estudiar estas coberturas. Sin embargo, se identificaron ajustes malos y moderados para la vegetación riparia (3 y $62 \%$ ) y las ciudades (72 y 66 \%) (Figura 8).

Por otro lado, el producto ESA-Landcover mostró valores altos de precisión del productor para los cultivos (91\%), pero la precisión del usuario fue moderada $(52,1 \%)$. Una situación similar se obtuvo para los pastizales (70 y $65 \%$, respectivamente). Este producto también arrojó resultados muy malos para la vegetación riparia (12 y $89 \%)$. Sin embargo, se obtuvieron excelentes resultados para el agua $(93,2$ y $98,2 \%)$ y las áreas urbanas (89 y $98 \%$ ) (Figura 8 ).

Figura 8 - Precisión del usuario (PU) y precisión del productor (PP) para MODIS Landcover y ESA Landcover en relación a los datos in situ.

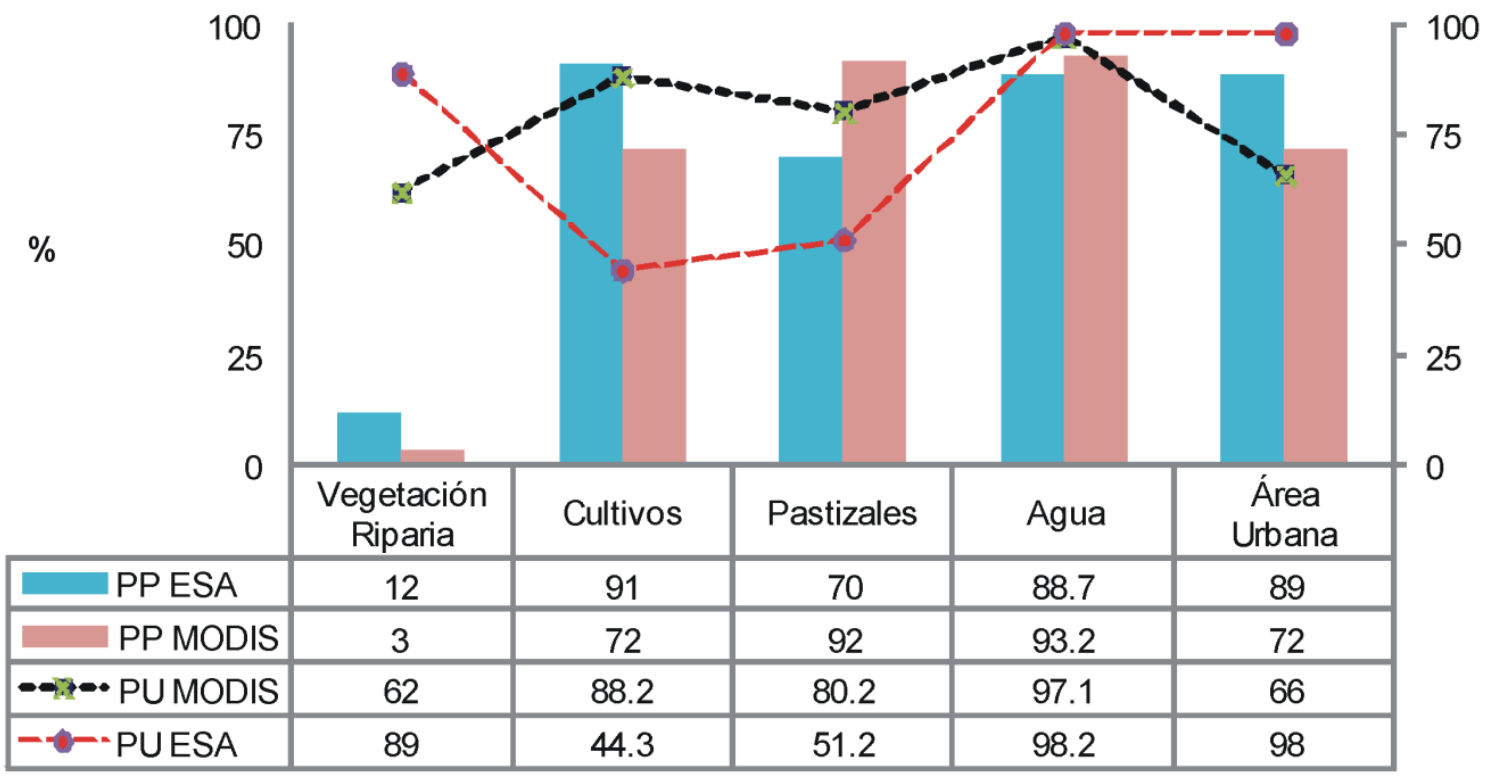

\section{DISCUSIÓN}

La teledetección permite monitorear de forma periódica la superficie terrestre, brindando un extenso volumen de datos y por lo tanto, realizar estudios de los cambios espacio-temporales que se observan sobre la superficie terrestre (RODRIGUEZ-GALIANO \& CHICA-RIVAS, 2014). En este sentido, la generación de un mapa de coberturas del suelo a escala anual es una herramienta fundamental para conocer las características de los paisajes, principalmente los semiáridos (BRENDEL et al., 2019). Su diseño y confección requieren del análisis de numerosas imágenes satelitales, recorrido del terreno de estudio y la implementación de instrumental específico, con el objetivo de generar un mapa de coberturas del suelo con gran precisión y excelentes ajustes. En este contexto, se destaca que la aplicación de índices espectrales de vegetación, suelos y agua favorecen la discriminación de las coberturas del suelo, incrementando el área de las muestras espaciales y generando productos con mejores resultados (SZANTOI et al., 2013; MUSHORE et al., 2017, entre otros). Además, existen

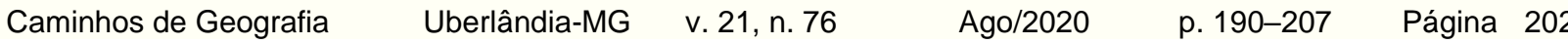


Validación de productos satelitales a partir de mediciones in situ para el monitoreo de coberturas del suelo en el sur de la Región Pampeana (Argentina)
Federico Ferrelli

Andrea Soledad Brendel

Gerardo Miguel Eduardo Perillo María Cintia Piccolo

numerosas investigaciones que demuestran que el método de Máxima Verosimilitud es el más preciso para clasificar las coberturas del suelo (GUERCHMAN et al., 2003; PAL \& ZIAUL, 2017; ANUROGO et al., 2018).

Por lo mencionado, los productos de MODIS-Landcover y ESA-Landcover surgen como una herramienta valiosa, dado que podrían reducir costos económicos para realizar estudios sobre las variaciones de las coberturas del suelo en una región. Estos han sido aplicados mundialmente con éxito, permitiendo analizar la variación de las coberturas del suelo ante distintos eventos extremos de precipitación (p.ej., FERRELLI, 2017). Además, han favorecido el estudio de las cubiertas terrestres en distintas partes del planeta en conjunto con imágenes satelitales de mayor resolución espacial (ZHANG \& ROY, 2017; AL-HANDAM et al., 2017; KARVONEN et al., 2018; LI et al., 2018). En este sentido, estos productos representan fuentes de datos que favorecen el análisis de las variaciones de las coberturas del suelo en las cuencas hidrográficas de Argentina con buenos resultados. EI MODISLandcover identificó, con excelentes ajustes, las coberturas de pastizales y cultivos, mientras que el ESA-Landcover lo fue para las ciudades y los cuerpos de agua. Las áreas semiáridas del mundo presentan una gran variabilidad en las coberturas del suelo, producto de la irregularidad de las precipitaciones (BOHN et al., 2016; ALIAGA et al., 2016). Los rendimientos escasos de los cultivos como consecuencia de las sequias son frecuentes en esta cuenca, por lo que su monitoreo con información satelital resulta fundamental para afrontar esta problemática. Por ello, se deberían profundizar las estrategias de adaptación de la población a la ocurrencia de eventos extremos de precipitación con vistas a reducir los efectos negativos que tiene la variabilidad pluviométrica sobre estos espacios (WENDEL, 2006).

\section{CONSIDERACIONES FINALES}

La determinación de las coberturas del suelo a campo es una tarea costosa que requiere de gran cantidad de instrumental, análisis de datos y testeo de distintos métodos de clasificación para generar un producto con excelentes ajustes. En este trabajo el análisis de productos provistos por fuentes indirectas demostró que si bien alguno de ellos sobreestiman o subestiman las coberturas del suelo, ambos tienen gran utilidad para ser aplicados en cuencas hidrográficas de clima semiáridos. Los resultados presentados constituyen una base de datos esenciales para el monitoreo de las coberturas del suelo en las cuencas de clima templado y semiárido de Argentina. Los mismos podrían servir de base para el ordenamiento del territorio y para orientar políticas públicas destinadas a conservar los recursos naturales y las actividades económicas de la población.

\section{AGRADECIMIENTOS}

Los autores desean agradecer al Consejo Nacional de Investigaciones Científicas y a la Universidad Nacional del Sur (CONICET - UNS) por el financiamiento del presente trabajo. Además, a la Comisión Nacional de Actividades Espaciales (CONAE) por la proporción de datos satelitales, al LAAD y la ESA por los productos satelitales.

\section{REFERENCIAS}

AL-HAMDAN, M. Z., ODUOR, P., FLORES, A. I., KOTIKOT, S. M., MUGO, R., ABABU, J., \& FARAH, $\mathrm{H}$. Evaluating land cover changes in Eastern and Southern Africa from 2000 to 2010 using validated Landsat and MODIS data. International journal of applied earth observation and geoinformation, vol. 62, p. 8-26, 2017. https://doi.org/10.1016/j.jag.2017.04.007

ALIAGA, V. S., FERRELLI, F., ALBERDI-ALGARAÑAZ, E. D., BOHN, V. Y., \& PICCOLO, M. C. Distribution and variability of precipitation in the Pampas, Argentina. Cuadernos de investigación Geográfica, vol. 42(1), p. 261-280, 2016. https://doi.org/10.18172/cig.2867

ALRABABAH, M. A. \& ALHAMAD, M. N. Land use/cover classification of arid and semi-arid Mediterranean landscapes using Landsat ETM. International journal of remote sensing, vol. 27, no 13, p. 2703-2718, 2006. https://doi.org/10.1080/01431160500522700

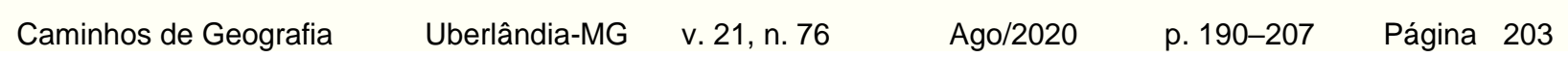


Validación de productos satelitales a partir de mediciones in situ para el monitoreo de coberturas del suelo en el sur de la Región Pampeana (Argentina)
Federico Ferrelli

Andrea Soledad Brendel

Gerardo Miguel Eduardo Perillo María Cintia Piccolo

ANUROGO, W. \& LUBIS, M. Z. Modified soil-adjusted vegetation index in multispectral remote sensing data for estimating tree canopy cover density at rubber plantation. Journal of Geoscience, Engineering, Environment, and Technology, vol. 3, no 1, p. 15-24, 2018. https://doi.org/10.24273/igeet.2018.3.01.1003

BENNIOU, R., \& BAHLOULI, F. Climate Change and Agriculture Conservation in Semi-aride Environment. Energy Procedia, vol. 74, p. 25-31, 2015. https://doi.org/10.1016/j.egypro.2015.07.516

BOHN, V. Y., DELGADO, A. L., PICCOLO, M. C., \& PERILLO, G. M. Assessment of climate variability and land use effect on shallow lakes in temperate plains of Argentina. Environmental Earth Sciences, vol. 75(9), 818, 2016. https://doi.org/10.1007/s12665-016-5569-6

BRENDEL, A.S. Estudio integral de los recursos hídricos y las coberturas del suelo de la cuenca media y baja del río Sauce Grande (Argentina). Tesis de doctor en geografía. Departamento de Geografía y Turismo, Universidad Nacional del Sur, 189 p., 2020.

BRENDEL, A. S., FERRELLI, F., PICCOLO, M. C., \& PERILLO, G. M. Assessment of the effectiveness of supervised and unsupervised methods: maximizing land-cover classification accuracy with spectral indices data. Journal of Applied Remote Sensing, vol.13(1), p. 014503, 2019. https://doi.org/10.1117/1.JRS.13.014503

BRENDEL, A., DUTTO, M. S., MENÉNDEZ, M. C., HUAMANTINCO CISNEROS, M. A., \& PICCOLO, M. C. Wind pattern change along a period of coastal occurrence variation of a stinging medusa on a SW Atlantic beach, Anuario do Insituto do Geociências, vol. 40 (3), p. 303-315, 2017a. https://doi.org/10.11137/2017 $3303 \quad 315$

BRENDEL, A., BOHN, V. Y., \& PICCOLO, M. C. Efecto de la variabilidad climática sobre el estado de la vegetación y la cobertura de agua en una cuenca de clima templado (Argentina), Geociências, vol. 40, p. 5-16, $2017 \mathrm{~b}$.

CARMONA, F., RIVAR, R. THOMAS, L. \& MARINO, B. Caracterización espectral del estuario del río Quequén Grande por medio de imágenes Landsat. en CARMONA, F. \& OCAMPO, D. (eds.) Teledetección: Recientes aplicaciones en la Región Pampeana, Tandil, Buenos Alres Argentina, p. 1129. 2011.

CHAVEZ Jr, P. S. An improved dark-object subtraction technique for atmospheric scattering correction of multispectral data. Remote sensing of environment, vol. 24(3), p. 459-479, 1988. https://doi.org/10.11137/201720516

CHEN, J., CHEN, J., LIAO, A., CAO, X., CHEN, L., CHEN, X., ... \& ZHANG, W. Global land cover mapping at $30 \mathrm{~m}$ resolution: A POK-based operational approach. ISPRS Journal of Photogrammetry and Remote Sensing, vol. 103, p. 7-27, 2015. https://doi.org/10.1016/j.isprsjprs.2014.09.002

DORAISWAMY, P. C., HATFIELD, J. L., JACKSON, T. J., AKHMEDOV, B., PRUEGER, J., \& STERN, A. Crop condition and yield simulations using Landsat and MODIS. Remote sensing of environment, vol. 92(4), p. 548-559, 2004. https://doi.org/10.1016/j.rse.2004.05.017

ESA. Land Cover CCI Product User Guide Version 2. Tech. Rep. 2017. Disponible en: maps.elie.ucl.ac.be/CCI/viewer/download/ESACCI-LC-Ph2-PUGv2_2.0.pdf

FERRELLI, F. Variabilidad pluviométrica y sus efectos sobre las coberturas del suelo al sur de la provincia de Buenos Aires, Argentina. Revista Geográfica Venezolana, vol. 58, no 1, p. 26-37, 2017.

FERRELLI, F., \& ALIAGA, V. S. Variabilidad de las precipitaciones y sus efectos sobre la respuesta espacio-temporal de cuerpos de agua en la región pampeana, Argentina. Huellas, vol. (20), p. 242246, 2016. https://doi.org/10.19137/huellas-2016-2015 
Validación de productos satelitales a partir de mediciones in situ para el monitoreo de coberturas del suelo en el sur de la Región Pampeana (Argentina)
Federico Ferrelli Andrea Soledad Brendel Gerardo Miguel Eduardo Perillo María Cintia Piccolo

FERRELLI, F., BRENDEL, A. S., ALIAGA, V. S., PICCOLO, M. C., \& PERILLO, G. M. E. Climate regionalization and trends based on daily temperature and precipitation extremes in the south of the Pampas (Argentina). Cuadernos de Investigación Geográfica, vol. 45(1), p. 393-416, 2019. https://doi.org/10.18172/cig.3707

FERRELLI, F., BUSTOS, M. L., HUAMANTINCO CISNEROS, M. A. Y PICCOLO, M. C. Utilización de imágenes satelitales para el estudio de la distribución térmica en distintas coberturas del suelo de la ciudad de Bahía Blanca (Argentina). Revista de Teledetección, vol. 44, p. 31-42, 2015. https://doi.org/10.4995/raet.2015.4018

GUERSCHMAN, J. P., PARUELO, J. M., BELLA, C. D., GIALLORENZI, M. C., \& PACIN, F. Land cover classification in the Argentine Pampas using multi-temporal Landsat TM data. International Journal of Remote Sensing, vol. 24(17), p. 3381-3402, 2003. https://doi.org/10.1080/0143116021000021288

HUETE, A. A soil-adjusted vegetation index (SAVI). Remote sensing of environment, vol. 25, p. 295309, 1988. https://doi.org/10.1016/0034-4257(88)90106-X

KARVONEN, V., RIBARD, C., SÄDEKOSKI, N., TYYSTJÄRVI, V., \& MUUKKONEN, P. Comparing ESA land cover data with higher resolution national datasets. Creating, managing, and analysing geospatial data and databases in geographical themes, p. 26-45, 2018.

KOLIOS, S., \& STYLIOS, C. D. Identification of land cover/land use changes in the greater area of the Preveza peninsula in Greece using Landsat satellite data. Applied Geography, vol. 40, p. 150-160, 2013. https://doi.org/10.1016/j.apgeog.2013.02.005

LI, W., MACBEAN, N., CIAIS, P., DEFOURNY, P., LAMARCHE, C., BONTEMPS, S., ... \& PENG, S. Gross and net land cover changes in the main plant functional types derived from the annual ESA CCI land cover maps (1992-2015). 2018. https://doi.org/10.5194/essd-2017-74

LOBELL, D. B. The use of satellite data for crop yield gap analysis. Field Crops Research, vol. 143, p. 56-64, 2013. https://doi.org/10.1016/j.fcr.2012.08.008

LIU, H. Q., \& HUETE, A. A feedback based modification of the NDVI to minimize canopy background and atmospheric noise. IEEE transactions on Geoscience and Remote Sensing, vol. 33(2), p. 457465, 1995. https://doi.org/10.1109/TGRS.1995.8746027

MANANDHAR, R., ODEH, I. O., \& ANCEV, T. Improving the accuracy of land use and land cover classification of Landsat data using post-classification enhancement. Remote Sensing, vol. 1(3), p. 330-344, 2009. https://doi.org/10.3390/rs1030330

MCFEETERS, S. K. The use of the Normalized Difference Water Index (NDWI) in the delineation of open water features. International journal of remote sensing, vol. 17(7), p. 1425-1432, 1996. https://doi.org/10.1080/01431169608948714

MUSHORE, T. D., MUTANGA, O., ODINDI, J., \& DUBE, T. Assessing the potential of integrated Landsat 8 thermal bands, with the traditional reflective bands and derived vegetation indices in classifying urban $\begin{array}{lllll}\text { landscapes. Geocarto } & \text { international, vol. } & 32(8), & \text { p. } & 886-899,\end{array}$ https://doi.org/10.1080/10106049.2016.1188168

NICLÒS, R., ESTRELLA, M. J., VALIENTE, J. A., Y BARBERÀ, M. J. Clasificación periódica de coberturas terrestres a escala regional con imágenes MODIS. GeoFocus. Revista Internacional de Ciencia y Tecnología de la Información Geográfica, vol. (10), p. 1-17, 2010.

NIRAULA, R. R., GILANI, H., POKHAREL, B. K., \& QAMER, F. M. Measuring impacts of community forestry program through repeat photography and satellite remote sensing in the Dolakha district of Nepal. Journal of environmental management, vol. 126, p. 20-29, 2013. https://doi.org/10.1016/j.jenvman.2013.04.006

PAL, S., \& ZIAUL, S. K. Detection of land use and land cover change and land surface temperature in English Bazar urban centre. The Egyptian Journal of Remote Sensing and Space Science, vol. 20(1), p. 125-145, 2017. https://doi.org/10.1016/j.ejrs.2016.11.003 
Validación de productos satelitales a partir de mediciones in situ para el monitoreo de coberturas del suelo en el sur de la Región Pampeana (Argentina)
Federico Ferrelli

Andrea Soledad Brendel

Gerardo Miguel Eduardo Perillo María Cintia Piccolo

PEKEL, J. F., COTTAM, A., GORELICK, N., \& BELWARD, A. S. High-resolution mapping of global surface water and its long-term changes. Nature, vol. 540(7633), p. 418-422, 2016. https://doi.org/10.1038/nature20584

QI, J., CHEHBOUNI, A., HUETE, A. R., KERR, Y. H., \& SOROOSHIAN, S. A modified soil adjusted vegetation index, Remote Sensing of Environment, vol. 48 (2), p. 119-126, 1994. https://doi.org/10.1016/0034-4257(94)90134-1

ROBINSON, N. P., ALLRED, B. W., JONES, M. O., MORENO, A., KIMBALL, J. S., NAUGLE, D. E., ... \& RICHARDSON, A. D. A dynamic Landsat derived normalized difference vegetation index (NDVI) product for the conterminous United States. Remote Sensing, vol. 9(8), p. 863, 2017. https://doi.org/10.3390/rs9080863

RODRIGUEZ-GALIANO, V. F., \& CHICA-RIVAS, M. Evaluation of different machine learning methods for land cover mapping of a Mediterranean area using multi-seasonal Landsat images and Digital Terrain Models. International Journal of Digital Earth, vol. 7(6), p. 492-509, 2014. https://doi.org/10.1080/17538947.2012.748848

ROUSE, J. W., HAAS, R. H., SCHELL, J. A., \& DEERING, D. W. Monitoring vegetation systems in the Great Plains with ERTS. NASA special publication, 351, p.309,1974.

SCHROEDER, T. A., COHEN, W. B., SONG, C., CANTY, M. J., \& YANG, Z. Radiometric correction of multi-temporal Landsat data for characterization of early successional forest patterns in western Oregon. Remote sensing of environment, vol. 103(1), p. 16-26, 2006. https://doi.org/10.1016/..rse.2006.03.008

SONG, D. X., HUANG, C., SEXTON, J. O., CHANNAN, S., FENG, M., \& TOWNSHEND, J. R. Use of Landsat and Corona data for mapping forest cover change from the mid-1960s to 2000s: Case studies from the Eastern United States and Central Brazil. ISPRS Journal of Photogrammetry and Remote
Sensing, vol.
103 ,
p.
81-92,
2015.

https://doi.org/10.1016/j.isprsjprs.2014.09.005

Sreedhar, Y., Nagaraju, A., \& Krishna, G. M. (2016). An Appraisal of Land Use/Land Cover Change Scenario of Tummalapalle, Cuddapah Region, India-A Remote Sensing and GIS Perspective. Advances in Remote Sensing, vol. 5(4), p. 232-245, 2016. https://doi.org/10.4236/ars.2016.54019

SZANTOI, Z., ESCOBEDO, F., ABD-ELRAHMAN, A., SMITH, S., \& PEARLSTINE, L. Analyzing finescale wetland composition using high resolution imagery and texture features. International Journal of Applied Earth Observation and Geoinformation, vol. 23, p. 204-212, 2013. https://doi.org/10.1016/j.jag.2013.01.003

The Level-1 and Atmosphere Archive \& Distribution System (LAADS) Distributed Active Archive Center (DAAC),

TULBURE, M. G., \& BROICH, M. Spatiotemporal dynamic of surface water bodies using Landsat timeseries data from 1999 to 2011. ISPRS Journal of Photogrammetry and Remote Sensing, vol. 79, p. 44-52, 2013. https://doi.org/10.1016/j.isprsjprs.2013.01.010

WANDEL, J. Adaptation, adaptive capacity and vulnerability, Global Environmental Change, vol. 16, p. 282-292, 2006. https://doi.org/10.1016/i.gloenvcha.2006.03.008

WILLIAMSON, C. E., SAROS, J. E., VINCENT, W. F., \& SMOL, J. P. Lakes and reservoirs as sentinels, integrators, and regulators of climate change. Limnology and Oceanography, vol. 54(6part2), p. 22732282, 2009. https://doi.org/10.4319/lo.2009.54.6 part 2.2273 
Validación de productos satelitales a partir de mediciones in

Federico Ferrelli situ para el monitoreo de coberturas del suelo en el sur de

WILSON, E. H., \& SADER, S. A. Detection of forest harvest type using multiple dates of Landsat TM imagery. Remote Sensing of Environment, vol. 80(3), p. 385-396, 2002. https://doi.org/10.1016/S0034-4257(01)00318-2

ZHANG, H. K., \& ROY, D. P. Using the $500 \mathrm{~m}$ MODIS land cover product to derive a consistent continental scale $30 \mathrm{~m}$ Landsat land cover classification. Remote Sensing of Environment, vol. 197, p.15-34, 2017. https://doi.org/10.1016/j.rse.2017.05.024

Recebido em: 23/04/2020

Aceito para publicação em: 26/06/2020 